\title{
Multidrug-resistant bacteria among patients with ventilator- associated pneumonia in an emergency intensive care unit, Egypt
}

Magda M. Azzab', Rehab H. El-Sokkary', Mohamed M. Tawfeek² and Manar G. Gebriel'

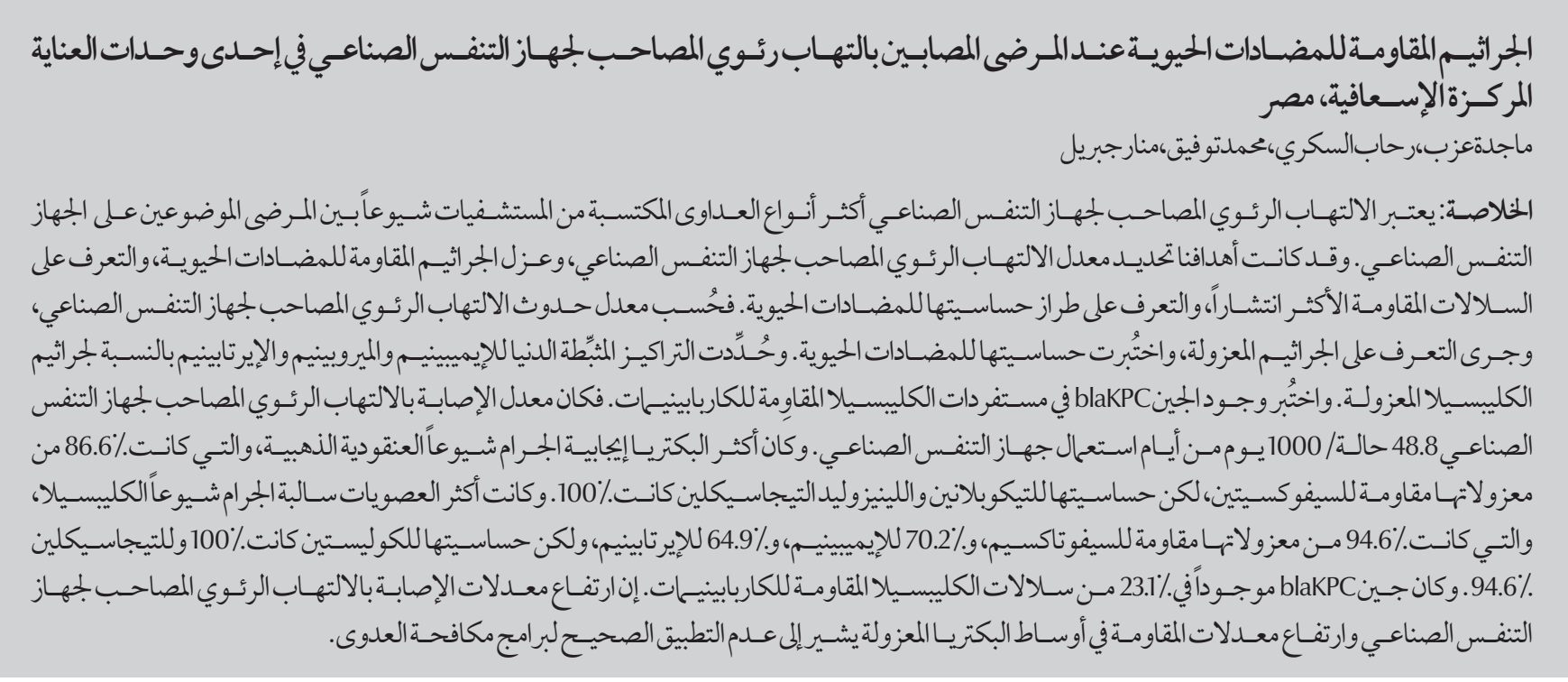

ABSTRACT Ventilator-associated pneumonia (VAP) is the most common hospital-acquired infection among mechanically ventilated patients. Our objectives were to determine the incidence of VAP, isolate multidrug-resistant bacteria, identify the most prevalent resistant strains and identify their antibiotic susceptibility pattern. The VAP rate was calculated. The isolated microbes were identified and tested for antibiotic susceptibilities. The minimum inhibitory concentrations were determined of imipenem, meropenem and ertapenem for Klebsiella isolates. Klebsiella isolates resistant to carbapenems were tested for the presence of the blaKPC gene. The VAP incidence density rate was 48.8 incidences/1 000 ventilator days. The most common Gram-positive organism was Staphylococcus aureus, of which $86.6 \%$ of isolates were resistant to cefoxitin, but $100 \%$ were sensitive to teicoplanin, linezolid and tigecycline. The most common Gram-negative bacillus was Klebsiella, of which 94.6\% of isolates were resistant to cefotaxime, $70.2 \%$ to imipenem, and $64.9 \%$ to ertapenem, but $100 \%$ were sensitive to colistin and $94.6 \%$ were sensitive to tigecycline. Of the carbapenem-resistant Klebsiella strains, $23.1 \%$ had the blaKPC gene. The high rates of VAP and the high rates of resistance among isolated organisms point to improper implementation of infection control programmes.

Bactéries multirésistantes parmi les patients atteints de pneumonie associée à la ventilation dans une unité de soins intensifs d'urgence, Égypte

RÉSUMÉ La pneumonie sous ventilation assistée (PVA) est la forme la plus courante d'infections nosocomiales contractées par les patients sous ventilation artificielle. L'objectif de la présente étude consistait à déterminer l'incidence de la PVA, à isoler les bactéries multirésistantes, et à identifier les souches résistantes les plus prévalentes ainsi que leur profil de sensibilité aux antibiotiques. Le taux de PVA a été calculé. Les microbes isolés ont été identifiés et leur sensibilité aux antibiotiques a été testée. Les concentrations minimales inhibitrices ont été déterminées pour l'imipénème, le méropénème et l'ertapénem pour les isolats de Klebsiella. Les isolats de Klebsiella résistants aux carbapénèmes ont été testés afin de déterminer la présence du gène blaKPC. Le taux de PVA était de 48,8 cas/1000 jours de ventilation. L'organisme à Gram positif le plus courant était Staphylococcus aureus, dont $86,6 \%$ des isolats étaient résistants à la céfoxitine, mais $100 \%$ étaient sensibles à la teicoplanine, au linézolide et à la tigécycline. Le bacille à Gram négatif le plus courant était Klebsiella, dont 94,6\% des isolats étaient résistants à la céfotaxime, 70,2 \% à l'imipénème, et 64,9\% à l'ertapénem, mais 100 \% étaient sensibles à la colistine et 94,6 \% à la tigécycline. Parmi les souches de Klebsiella résistantes aux carbapénèmes, 23,1 \% contenaient le gène blaKPC. Les taux élevés de PVA et de résistance parmi les organismes isolés indiquent une mise en œuvre inadéquate des programmes de lutte contre les infections.

${ }^{7}$ Medical Microbiology and Immunology Department, Faculty of Medicine, Zagazig University, Egypt. ${ }^{2}$ Anaesthesia and Surgical Intensive Care Department, Faculty of Medicine, Zagazig University, Egypt. (Correspondence to Rehab H. El-Sokkary: Rehab_elsokkary@yahoo.com.)

Received: 23/02/16; accepted: 02/10/16 


\section{Introduction}

Ventilator-associated pneumonia (VAP) has been reported to be the most serious healthcare-associated infection in intensive care units (ICUs) (1). VAP is defined as pneumonia developing more than 48 hours after endotracheal intubation and initiation of mechanical ventilation. It also includes pneumonia developing after extubation (2). Early-onset VAP is usually less severe, is associated with better prognosis and is likely to be caused by antibiotic-sensitive bacteria. Late-onset VAP is caused by multidrug-resistant (MDR) pathogens and is associated with increased morbidity and mortality. The types of MDR strains that cause VAP vary from one hospital to another, by patient population and by comorbid condition (2).

Enterobacteriaceae producing Klebsiella pneumoniae carbapenemase (KPC) are rapidly disseminating in several countries and geographical areas. This spread of KPC enzymes makes the organisms a potential threat to current antibiotic-based treatment protocols (3). Deficient infection-control procedures and improper antibiotic administration are the main causes for the emergence of MDR strains. Thus, the implementation of an antibiotic stewardship programme has become a vital necessity (4).

This study was conducted as part of a comprehensive educational programme and antibiotic stewardship programme in an ICU to determine the incidence of VAP, to isolate MDR organisms from VAP patients, and to identify the most prevalent resistant strains, as well as their patterns of antibiotic susceptibility.

\section{Methods}

A prospective surveillance study was conducted in the Infection Control Laboratory of the Microbiology
Department at the Faculty of Medicine, Zagazig University, Egypt. It was carried out during 12 months (March 2014 to February 2015).

\section{Participants}

Enrolled cases were selected from patients admitted to the emergency ICU. Patients were included if they were mechanically ventilated for more than 48 hours. Patients were excluded if there was evidence of chest infection prior to intubation, if they were intubated patients who had been admitted from another hospital, or if they were immunocompromised.

Using Epi Info 6 (US Centers for Disease Control and Prevention, Atlanta, GA, USA), the sample size was calculated assuming a statistical power of $80 \%, 95 \%$ confidence intervals, the attendance rate of mechanically ventilated patients at the investigated unit was 500 , and a prevalence of VAP of $57.14 \%$ (5). We investigated 83 cases owing to the assumed $20 \%$ non-response rate. Patients were selected by systematic random sampling; every sixth admitted patient fulfilling the inclusion criteria was enrolled.

VAP was suspected using clinical or radiological criteria, or a combination of these, and confirmed by microbiological examination of endotracheal aspirate (6). The study was approved by the Institutional Review Board of the hospital, and informed written consent was obtained from enrolled patients or their relatives.

\section{Setting}

The setting was a 15-bed emergency ICU; it is the only emergency ICU in the Zagazig University Hospital. It serves trauma patients and surgical emergency patients. The ICU is managed by qualified critical care doctors, 24 hours a day and 7 days a week, with a nurse to patient ratio of 1:2 during both the day and night shifts, and 1 clinical pharmacist. The ICU has an active infection prevention and control programme, managed by one infection control specialist, four infection control nurses and one infection control link nurse.

Antibiotics are initially prescribed empirically and then de-escalation takes place according to results from culture and sensitivity testing (7). Before the study, the most frequently administered antibiotics were glycopeptide antibiotics, third-generation cephalosporins and carbapenems.

\section{Microbiological tests}

Once VAP was clinically suspected, specimen collection was ordered by the critical care doctor on duty. The specimen was then sent to the infection control laboratory for microbiological confirmation. Endotracheal aspirate was collected using aseptic technique (8). Gram-stained smears were examined microscopically. A neutrophil count of $>25$ pus cells/low-power field and $>1$ bacterium per oil-immersion field were considered as diagnostic for the presence of infection (2).

Endotracheal aspirate was mechanically liquefied and homogenized by vortexing for 1 minute with sterile glass beads, followed by centrifugation at $3000 \mathrm{rpm}$ for 10 minutes (9). Each sample was cultured on blood agar, MacConkey agar and chocolate agar, then incubated at $37^{\circ} \mathrm{C}$ for 48 hours at $10 \% \mathrm{CO}_{2}$. Semiquantitative culture analysis was done according to the methods of Joseph et al. (10), using the four-quadrant technique and a calibrated $10 \mu \mathrm{L}$ loop. Based on the number of colonies in each quadrant, grades of $3+$ and $4+$ were considered as diagnostic growth thresholds and represented a colony count $>10^{6}$ colony forming units (or CFUs). The isolated bacteria were identified using standard microbiological techniques (11).

\section{Calculating VAP rates}

The rates of VAP were calculated as follows. 
- The incidence was calculated as the total number of cases of VAP among the population studied.

- The incidence density rate was the number of cases with VAP/ the number of ventilator days) x 1000, which gave the VAP rate per 1000 ventilator days.

\section{Testing for antibiotic susceptibility}

Isolates were tested for antimicrobial susceptibility by the modified
Kirby-Bauer disc diffusion method (12). Multidrug resistance was defined as bacteria that were not susceptible to at least one agent in three or more antimicrobial categories (13). Staphylococcus aureus ATCC 25923, Escherichia coli ATCC 25922 and Pseudomonas aeruginosa ATCC 27853 were used as quality control strains (American Type Culture Collection Global Bioresource Center, Manassas, VA, USA). Screening for carbapenemase production was done using the disc diffusion method and by determining the minimum inhibitory concentrations (MICs) for carbapenem. Confirmation was done using the modified Hodge test (12). The MICs of carbapenems for all Klebsiella isolates were determined using the tube dilution method (12). The antibiotics tested were imipenem, meropenem and ertapenem (El Nasr Co., Cairo, Egypt). Escherichia coli ATCC 25922 was used as the quality control strain.

\begin{tabular}{|c|c|c|c|c|}
\hline Parameters & $\begin{array}{l}\text { No. }(\%) \text { VAP cases } \\
(N=55)\end{array}$ & $\begin{array}{l}\text { No. }(\%) \text { non-VAP } \\
(N=28)\end{array}$ & $x^{2}$ & $P$ \\
\hline \multicolumn{5}{|l|}{ Sex } \\
\hline Male & $40(72.7)$ & $14(50)$ & 4.21 & 0.04 \\
\hline Female & $15(27.3)$ & $14(50)$ & & \\
\hline \multicolumn{5}{|l|}{ Age group } \\
\hline 0-10 & $4(7.3)$ & $4(14.3)$ & 2.24 & 0.69 \\
\hline $11-20$ & $10(18.2)$ & $4(14.3)$ & & \\
\hline $21-40$ & $16(29.1)$ & $5(17.8)$ & & \\
\hline $41-60$ & $14(25.4)$ & $8(28.6)$ & & \\
\hline$>60$ & $11(20)$ & $7(25)$ & & \\
\hline \multicolumn{5}{|l|}{ Reasons for admission } \\
\hline Polytrauma & $40(72.7)$ & $5(17.9)$ & 115.99 & $<0.0001$ \\
\hline Surgical emergency & $5(9.1)$ & $11(39.3)$ & & \\
\hline Respiratory failure & $4(7.4)$ & $6(21.4)$ & & \\
\hline Obstetric emergency & $3(5.4)$ & $2(7.1)$ & & \\
\hline Other & $3(5.4)$ & $4(14.3)$ & & \\
\hline \multicolumn{5}{|l|}{ Associated comorbidities } \\
\hline Hypertension & $16(29.1)$ & $7(25)$ & 0.15 & 0.69 \\
\hline Diabetes mellitus & $18(32.7)$ & $8(28.5)$ & 0.15 & 0.69 \\
\hline Chronic liver disease & $15(27.3)$ & $6(21.4)$ & 0.33 & 0.56 \\
\hline Renal disease & $5(9.1)$ & $2(7.1)$ & 0.09 & 0.76 \\
\hline Cardiac disease & $9(16.4)$ & $4(14.2)$ & 0.06 & 0.80 \\
\hline \multicolumn{5}{|l|}{ Duration of ventilation } \\
\hline$<5$ days (early-onset VAP) & $5(9.1)$ & NA & NA & NA \\
\hline$\geq 5$ days (late-onset VAP) & $50(90.9)$ & NA & & \\
\hline Mortality rate & $20(36.4)$ & $9(32.1)$ & 0.14 & 0.70 \\
\hline $\begin{array}{l}\text { No. of ventilator days: Mean (SD) } \\
\text { (total No. ventilator days }=1125 \text { ) }\end{array}$ & $17.25(13.00)$ & $6.28(3.1)$ & MW & 0.001 \\
\hline $\begin{array}{l}\text { No. days in intensive care unit : Mean }(S D) \\
\text { (total No. days in intensive care unit }=1268 \text { ) }\end{array}$ & $18.8(13.55)$ & $8.35(3.96)$ & MW & 0.001 \\
\hline Total No. of ventilator days before VAP & 350 & NA & NA & NA \\
\hline Mean (SD) APACHE II score & $21.5(2.93)$ & $18.75(3.9)$ & $3.28^{\mathrm{a}}$ & 0.002 \\
\hline
\end{tabular}

$N A=$ not applicable; MW: Mann-Whitney test .

${ }^{a}$ The Student's t test was used to determine statistical significance. 
For the modified Hodge test, the surface of a Mueller-Hinton agar plate was inoculated with a culture suspension of E. coli ATCC 25922. A disc of meropenem was placed in the centre of the plate. Three to five colonies of test organisms and quality control organisms were inoculated in a straight line from the edge of the disc to the edge of the plate. The streak was at least 20 $\mathrm{mm}$ to $25 \mathrm{~mm}$ in length. After overnight incubation, the plates were examined for enhanced growth around the streaks of the test organism and the quality control organism at the intersection of the streak and the zone of inhibition. The presence of enhanced growth indicated carbapenemase production and the absence of enhanced growth meant there was no carbapenemase production. $K$. pneumoniaeATCC BAA-1705 was used as the positive control for the test (12).

\section{Detecting the $b / a_{\mathrm{KPC}}$ gene in Klebsiella isolates}

DNA was extracted from isolated colonies using the QIAamp DNA Mini Kit (Qiagen, Hilden, Germany). Polymerase chain reaction (PCR) was performed to detect $b l a_{\mathrm{KPC}}$ genes $\left(b l a_{\mathrm{KPC}}-1\right.$ through $\left.b l a_{\mathrm{KPC}}-7\right)$ in Klebsiella isolates. PCR-GOLD Master Mix beads (Bioron Life Science, Ludwigshafen, Germany) were used for amplification. E. coli ATCC 25922 was used as a negative control and bla ${ }_{\mathrm{KPC}}$-carrying K. pneumoniae ATCC BAA-1705 was used as a positive control. The amplification was done as described elsewhere (14).

\section{Results}

A total of 83 mechanically ventilated patients were included in the study. Only 55 (66.3\%) patients fulfilled the diagnostic criteria for VAP (Table 1). All included cases with VAP presented with fever, leukocytosis, rales or bronchial breath sounds and recent-onset purulent sputum with an increase in respiratory secretions that required

\begin{tabular}{lc}
\hline Table 2 Bacteria isolated from $\mathbf{5 5}$ patients with ventilator-associated pneumonia ${ }^{\mathbf{a}}$ \\
\hline Bacterial species $^{\mathrm{b}}$ & Number $(\%)$ of isolates \\
Gram-positive & $15(17.4)$ \\
Staphylococcus aureus & $5(5.8)$ \\
Coagulase-negative Staphylococcus & $2(2.3)$ \\
Streptococcus pneumoniae & $1(1.2)$ \\
Enterococcus & $23(26.7)$ \\
Total & \\
Gram-negative & $37(43)$ \\
Klebsiella & $13(15.1)$ \\
Pseudomonas & $8(9.3)$ \\
Acinetobacter & $4(4.7)$ \\
Escherichia coli & $1(1.2)$ \\
Proteus & $63(73.3)$ \\
Total &
\end{tabular}

${ }^{a}$ The total number of bacterial isolates was 86 .

${ }^{b}$ Mixed bacterial isolates from 31 patients included 12 with Klebsiella plus Staphylococcus aureus, 7 with Klebsiella plus Acinetobacter, 5 with Klebsiella plus Pseudomonas, 2 with Pseudomonas plus Staphylococcus aureus, 2 with Escherichia coli plus Pseudomonas, 7 with Klebsiella plus Proteus, 7 with Klebsiella plus coagulase-negative Staphylococcus, and 7 with Pseudomonas plus Enterococcus.

suctioning. The incidence of VAP was $55 / 83^{\prime} 100=66.3 \%$. The incidence density rate was $55 / 1125^{\prime} 1000=$ $48.8 / 1000$ ventilator days.

Of the 55 patients diagnosed as having VAP, 31 patients (56.4\%) had polymicrobial infection (all of them were polytrauma patients) and the remaining 24 patients (43.6\%) had monomicrobial infection. Thus, the total number of isolates was 86 (Table 2). Five bacteria were isolated from five patients with early-onset VAP : two were Streptococcus pneumoniae, two were coagulasenegative staphylococci and one was Staphylococcus aureus. A total of 81 isolates were obtained from 50 patients with late-onset VAP.

The results of antibiotic susceptibility testing (Tables 3 and 4) were reported to the ICU team so the patients' treatment could be monitored. The data were included in the ICU database to inform the local antibiogram, which is an important adjunct for implementing the antibiotic stewardship programme. An infection control consultant experienced in clinical microbiology and infection prevention and control strategies assessed the patients' outcomes.
The mortality rate among the VAP patients was $36.4 \%(20 / 55)$. The remaining $63.6 \%(35 / 55)$ of patients were transferred to inpatient wards or the high dependency unit; in 10 patients, the infection was cured.

The MICs of carbapenems for Klebsiella isolates (37 isolates) are shown in Table 5. PCR identified the blaKPC gene in 6/26 (23.1\%) imipenem-resistant Klebsiella isolates. All isolates that were positive by PCR were resistant to carbapenem, when tested by both the disc diffusion and MIC methods.

\section{Discussion}

VAP is a form of hospital-acquired pneumonia that has a high mortality rate. The overall incidence of VAP in ICUs ranged from $10 \%$ to $70 \%$ during 2013 (2). The incidence of VAP in our ICU was $66.3 \%$ and the rate of VAP was $48.8 / 1000$ ventilator days. This was lower than the previous rates recorded from a respiratory ICU at Ain Shams University Hospital in Egypt; there, the VAP rate was $70.25 / 1000$ ventilator days, with a higher incidence of late-onset VAP (49.45 / 1000 ventilator days) 


\begin{tabular}{|c|c|c|c|c|c|c|c|c|c|c|c|c|}
\hline \multirow[t]{3}{*}{ Antibiotic } & \multicolumn{12}{|c|}{ No. (\%) isolates } \\
\hline & \multicolumn{3}{|c|}{$\begin{array}{l}\text { Staphylococcus aureus } \\
\qquad(N=15)\end{array}$} & \multicolumn{3}{|c|}{$\begin{array}{c}\text { Coagulase-negative } \\
\text { Staphylococcus } \\
(N=5)\end{array}$} & \multicolumn{3}{|c|}{$\begin{array}{l}\text { Streptococcus } \\
\text { pneumoniae } \\
\qquad(N=2)\end{array}$} & \multicolumn{3}{|c|}{$\begin{array}{l}\text { Enterococcus } \\
\qquad(N=1)\end{array}$} \\
\hline & $S$ & I & $\mathbf{R}$ & $\mathbf{S}$ & I & $\mathbf{R}$ & S & I & $\mathbf{R}$ & $\mathbf{S}$ & I & $\mathbf{R}$ \\
\hline \multicolumn{13}{|l|}{ Penicillins } \\
\hline Penicillin (10 units) & 0 & 0 & $15(100)$ & 0 & 0 & $5(100)$ & - & - & - & 0 & 0 & $1(100)$ \\
\hline \multicolumn{13}{|l|}{ Cephamycins } \\
\hline Cefoxitin (30 m) & $2(13.4)$ & 0 & $13(86.6)$ & $2(40)$ & 0 & $3(60)$ & - & - & - & - & - & - \\
\hline \multicolumn{13}{|l|}{ Glycopeptides } \\
\hline Teicoplanin (30 m) & $15(100)$ & 0 & 0 & $5(100$ & 0 & 0 & - & - & - & $1(100)$ & 0 & 0 \\
\hline Vancomycin & $15(100)$ & 0 & 0 & $5(100)$ & 0 & 0 & $2(100)$ & 0 & 0 & $1(100)$ & 0 & 0 \\
\hline \multicolumn{13}{|l|}{ Aminoglycosides } \\
\hline Gentamicin (10 m) & $2(13.3)$ & $1(6.7)$ & $12(80)$ & $1(20)$ & $1(20)$ & $3(60)$ & - & - & - & - & - & - \\
\hline Tobramycin (10 m) & $2(13.3)$ & 0 & $13(86.7)$ & $2(40)$ & $1(20)$ & $2(40)$ & - & - & - & - & - & - \\
\hline Amikacin (30 m) & $2(13.3)$ & 0 & $13(86.7)$ & $3(60)$ & 0 & $2(40)$ & - & - & - & - & - & - \\
\hline $\begin{array}{l}\text { Macrolides } \\
\text { Erythromycin (15 m) }\end{array}$ & $2(13.3)$ & $1(6.7)$ & $12(80)$ & $2(40)$ & $1(20)$ & $2(40)$ & $1(50)$ & 0 & $1(50)$ & 0 & $1(100)$ & 0 \\
\hline $\begin{array}{l}\text { Glycylcycline } \\
\text { Tigecycline (15 m) }\end{array}$ & $15(100)$ & 0 & 0 & $5(100)$ & 0 & 0 & $2(100)$ & 0 & 0 & $1(100)$ & 0 & 0 \\
\hline $\begin{array}{l}\text { Fluoroquinolones } \\
\text { Ciprofloxacin }(5 \mathrm{~m})\end{array}$ & $2(13.3)$ & $1(6.7)$ & $12(80)$ & $2(40)$ & 0 & $3(60)$ & - & - & - & 0 & $1(100)$ & 0 \\
\hline Levofloxacin (5 m) & $7(46.7)$ & 0 & $8(53.3)$ & $4(80)$ & $1(20)$ & 0 & $2(100)$ & 0 & 0 & $1(100)$ & 0 & 0 \\
\hline $\begin{array}{l}\text { Lincosamides } \\
\text { Clindamycin (2 m) }\end{array}$ & $6(40)$ & 0 & $9(60)$ & $4(80)$ & 0 & $1(20)$ & $2(100)$ & 0 & 0 & - & - & - \\
\hline \multicolumn{13}{|c|}{ Folate pathway inhibitors } \\
\hline $\begin{array}{l}\text { Trimethoprim/ } \\
\text { sulfamethoxazole } \\
(1.25 / 23.75 \mathrm{~m})\end{array}$ & $6(40)$ & 0 & $9(60)$ & $4(80)$ & $1(20)$ & 0 & $1(50)$ & $1(50)$ & 0 & - & - & - \\
\hline $\begin{array}{l}\text { Ansamycins } \\
\text { Rifampicin (5 m) }\end{array}$ & $7(46.7)$ & 0 & $8(53.3)$ & $4(80)$ & $1(20)$ & 0 & $2(100)$ & 0 & 0 & $1(100)$ & 0 & 0 \\
\hline \multicolumn{13}{|l|}{ Oxazolidinones } \\
\hline Linezolid (30 m) & $15(100)$ & 0 & 0 & $5(100)$ & 0 & 0 & $2(100)$ & 0 & 0 & $1(100)$ & 0 & 0 \\
\hline
\end{tabular}

$I=$ intermediate $: R=$ resistant. $S=$ sensitive

${ }^{a}$ Values are numbers (percentages) of isolates.

${ }^{b}$ Multidrug-resistance rates for each type of bacteria are: Staphylococcus aureus - 12/15(80\%); coagulase-negative Staphylococcus 3/5 (60\%); Streptococcus pneumoniae - 0; Enterococcus - 0; Gram-positive isolates - 15/23 (65.2)\%

' The test for the minimum inhibitory concentration for vancomycin was performed according to the recommendations of the Clinical and Laboratory Standards Institute (12).

than early-onset VAP $(20.82 / 1000$ ventilator days) (15). However, the recorded VAP rate in the current study is higher than a previous study performed in Egypt at the Nasser Institute's ICU (16); there, the VAP rate was 20.77 / 1000 ventilator days, with a higher incidence of early-onset VAP than late-onset VAP. Moreover, the VAP rate in our study was higher than that reported from an ICU in Saudi Arabia where it was $15.9 / 1000$ ventilator days (17), and it is also higher than the rate reported from 7 Indian ICUs, where it was $10.46 / 1000$ ventilator days (18).

A study conducted in 55 ICUs in 46 hospitals in 8 developing countries (Argentina, Brazil, Colombia, India, Mexico, Peru, Morocco and Turkey) found the overall VAP rate of 24.1 /1 000 ventilator days (19); however, this was lower than the rates recorded in the present study. In developed countries, the median number of cases ranged from 1.3 to $2.0 / 1000$ ventilator days in hospitals participating in the National Healthcare Safety Network (NHSN) system (20).

The lower rates recorded in developed countries could be due to strict implementation of infection control 


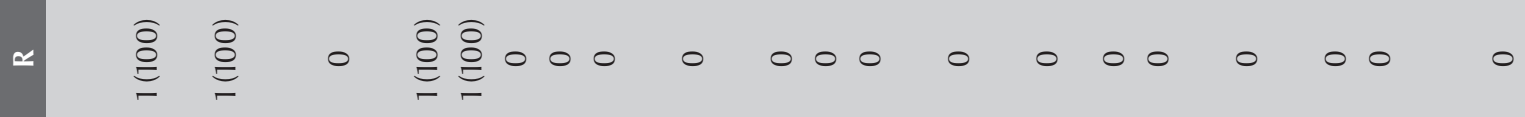

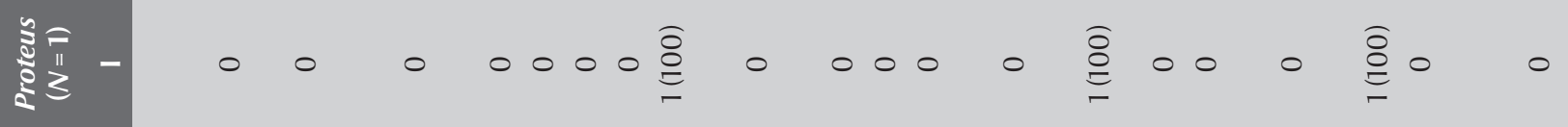

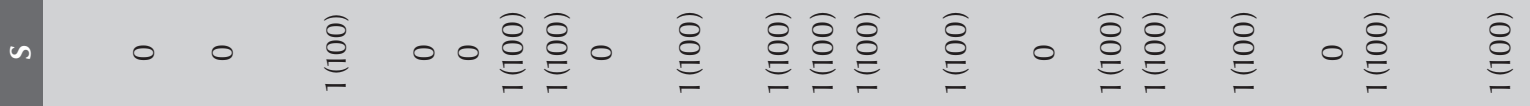

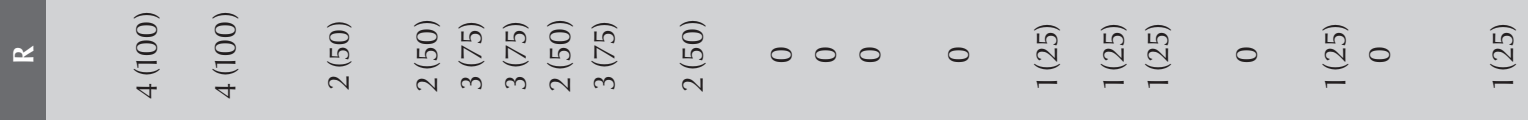

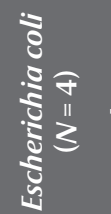

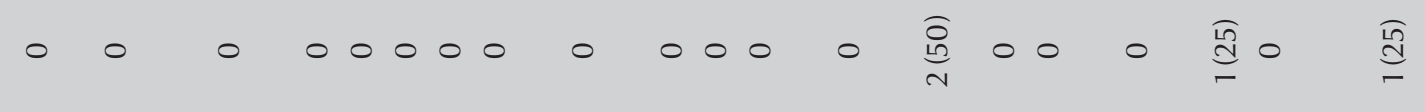

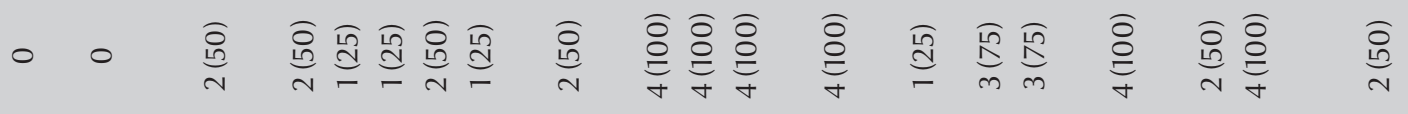

$\simeq$

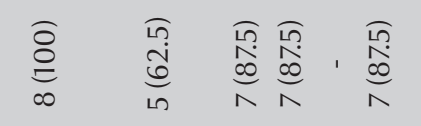

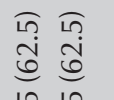

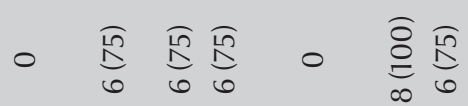

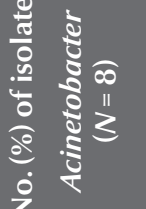
$0 \underset{-}{\stackrel{\overparen{n}}{g}}, 0$

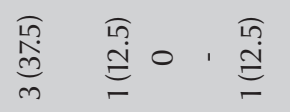

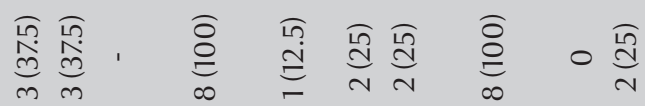

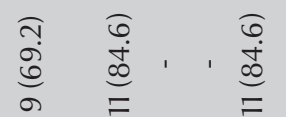

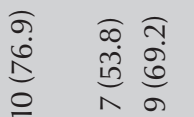

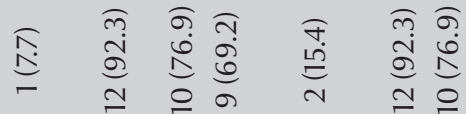

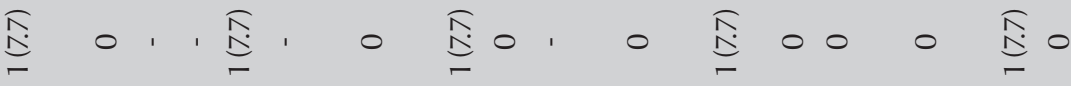

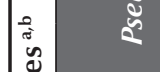

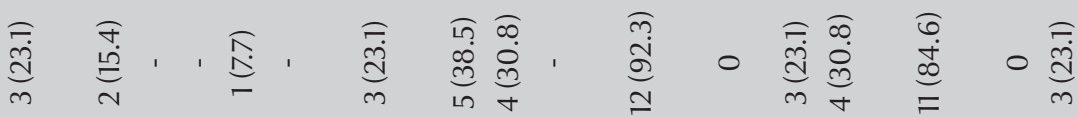

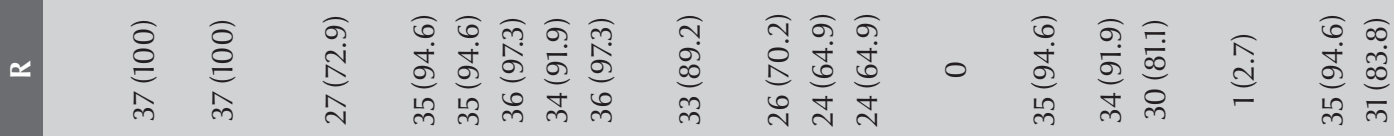

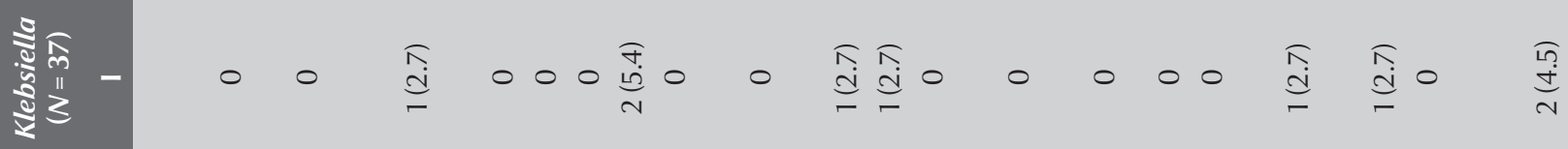

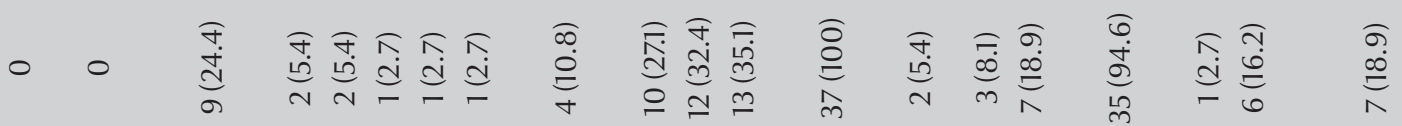

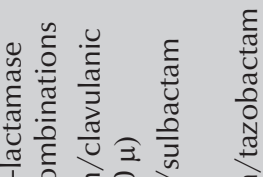

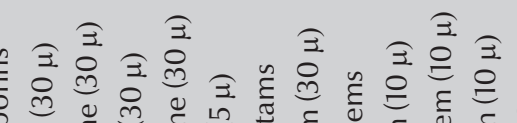

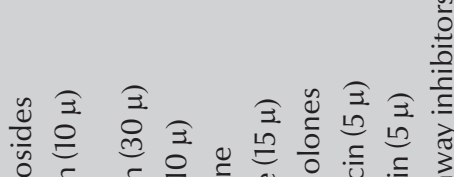


measures and continual annual surveillance at all hospitals that is aimed at decreasing infection rates, as well as to the better availability of resources and the increased awareness among all healthcare workers of measures to prevent and control infection (16). Thus, the high incidence of VAP and MDR in this study could be attributed to a lack of good infection control practices and the non-rational use of antibiotics; this highlights the importance of strictly following the protocols of antibiotic stewardship programmes.

The current study showed that the mean durations of mechanical ventilation and hospital stay, and mortality rates were higher in patients with VAP than in mechanically ventilated patients who did not develop pneumonia. These differences may be due to inappropriate treatment, bacteraemia associated with a virulent organism or the presence of an underlying medical condition. These findings confirm the importance of diagnosing VAP early and initiating appropriate antibiotic treatment as vital tools for preventing adverse outcomes.

The pathogens responsible for VAP vary according to the duration of mechanical ventilation, a patient's prior antibiotic exposure and the length of hospital stay. In this study, Gram-negative bacilli were found to be the most prevalent pathogens associated with $\operatorname{VAP}(63 / 86$ [73.3\%] of isolates); Klebsiella was associated with $43 \%(37 / 86)$; P. aeruginosa with 15.1\% (13/86); Acinetobacter baumannii with $9.3 \%(8 / 86)$; and E. coli with $4.7 \%$ (4/86). Some studies have found that $A$. baumannii is the most common organism causing VAP (2), but others found $P$. aeruginosa to be the most common organism causing $\operatorname{VAP}(4,21)$.

Klebsiella has also been recognized as an important cause of infections, and various environmental reservoirs have been identified. Irrespective of the primary source, it seems that the most significant reservoir for the microorganism is the digestive tract of colonized patients, and that transmission occurs mostly via the hands of nursing staff (22). Low rates of compliance with hand hygiene practices have been recorded among healthcare workers in the ICU investigated in this study (RH El-Sokkary, R Elsaid Tash, unpublished data, 2014). This could explain the high prevalence of Klebsiella revealed in the current study.

Out of 86 culture-positive samples, 71 isolates $(82.6 \%)$ were found to be MDR. Among Gram-positive isolates, $15 / 23(65.2 \%)$ were found to be MDR; for Gram-negative isolates, 56/63 (88.8\%) were found to be MDR. Similar results were reported in a tertiary care hospital in Nepal where $66.7 \%$ of bacteria isolated in postoperative wound infections was MDR: $83.33 \%$ of Gram-negative bacteria and $47.5 \%$ of Gram-positive isolates were MDR (23).

The antibiotic susceptibility patterns of organisms isolated in this study are being used to provide guidelines for empirically prescribing antibiotics in the ICU studied. Penicillin is not recommended. For Staphylococcus aureus, cefoxitin, erythromycin and ciprofloxacin are no longer recommended as first-line therapy due to the high incidence of resistance. Vancomycin, teicoplanin, linezolid and tigecycline were most effective against Gram-positive cocci causing VAP, so they should be saved for life-threatening infections.

Antibiotic resistance is high among Gram-negative bacilli; most of the tested antibiotics are not recommended for use. This highlights the urgent need for a local antibiogram to guide the prescription of antibiotics. Tigecycline and colistin have been found to be the most effective agents against Gramnegative isolates, so they should be reserved for life-threatening infections (24), although a risk assessment of the patient's general condition is highly recommended for colistin.

The high rates of antibiotic resistance reported for Klebsiella isolates may be explained by the rapid transmission of determinants of antibiotic resistance between different species of enteric Gram-negative bacilli, a condition enhanced by the lack of adherence to infection control standards (25). The extensive use of $\beta$-lactam antibiotics, including third-generation cephalosporins, for treating infections is another factor that helps increase the prevalence of resistant isolates.

The high rates of resistance reported in this study are similar to those previously reported for device-associated infection at Cairo University Hospital, with $70 \%$ of tested E. coli and K. pneumoniae isolates found to produce extendedspectrum $\beta$-lactamases (26). In contrast, in the United States, only $20 \%$ of the $E$. coli and $K$. pneumoniae isolates reported to the NHSN have extended-spectrum cephalosporin resistance. Resistance rates for other organisms are also substantially higher in Egypt. For instance, 100\% of Acinetobacter spp. isolates from hospital-acquired infections in Egypt are MDR versus approximately $70 \%$ of isolates in the NHSN; 93\% of Staphylococcus aureus isolates tested in Egypt were methicillin resistant compared with 50\% in the NHSN (27).

In the current study, the most common organisms isolated from VAP cases were Gram-negative bacilli. Similar results have been reported from an Egyptian study (16) and a study conducted in Saudi Arabia (17). In a study performed in ICUs in different hospitals in an urban town in India (2), the antibiogram of the isolated Gram-negative bacilli showed A. baumannii (46.22\% of isolates) and P. aeruginosa (18.68\%) to be MDR. All (100\%) A. baumannii isolates were resistant to ampicillin; and $88.6 \%$ were resistant to cefotaxime, $78 \%$ to ceftazidime, $48 \%$ to amikacin, $42.4 \%$ to imipenem, and $42.4 \%$ to meropenem. P. aeruginosa isolates also had a $100 \%$ resistance rate to ampicillin, $47.2 \%$ resistance to cefotaxime, $47.2 \%$ resistance to ceftazidime and $18.6 \%$ to imipenem and meropenem. Staphylococcus aureus 


\begin{tabular}{|c|c|c|c|}
\hline \multirow[t]{2}{*}{ Antimicrobial agent } & \multicolumn{3}{|c|}{ Minimum inhibitory concentration } \\
\hline & S & $\mathbf{I}$ & $\mathbf{R}$ \\
\hline Imipenem & $11(29.7)$ & $2(5.4)$ & $24(64.9)$ \\
\hline Meropenem & $12(32.4)$ & $2(5.4)$ & $23(62.2)$ \\
\hline Ertapenem & $14(37.8)$ & $3(8.1)$ & $20(54.1)$ \\
\hline
\end{tabular}

$I=$ intermediate $;=$ resistant $S=$ sensitive

${ }^{a}$ Values are numbers (percentages) of isolates.

${ }^{b}$ The MIC50/MIC9O values of imipenem, meropenem and ertapenem were, respectively, 4/16ug/ml, 4/16 ug/ml and 2/8 uglml

was the most common Gram-positive isolate, and $11.44 \%$ of isolates were resistant to cefoxitin.

In this study, among the Klebsiella isolates, $26 / 37(70.2 \%)$ were resistant to imipenem by the disc diffusion method, 24/37 (64.9\%) were resistant to meropenem and 24/37 (64.9\%) were resistant to ertapenem. This is much higher than the rates reported by Marschall et al. (28), who found only $2.9 \%$ of isolates were resistant to one or more carbapenems at Barnes-Jewish Hospital in St. Louis, MO, United States. However, surveillance cultures from hospitals in the New York City area reported rates of carbapenem resistance among Klebsiella isolates ranging up to $24 \%$ (29). This high percentage of resistant strains may be explained by the observations of Tumbarello et al. (30) who found that a history of chronic disease; prolonged hospitalization; undergoing invasive procedures, mechanical ventilation, or urinary catheterization; as well as previous treatment with antimicrobials were all associated with carbapenemase production.

Freitas et al. (31) reported that the use of carbapenems, and mainly imipenem, has been implicated as one of the major risk factors for the induction of carbapenemase-resistance genes. This coincides with the current study, in which some patients infected with imipenem-resistant Klebsiella had a history of taking $\beta$-lactam antibiotics: carbapenems are a member of this class of antibiotics.

In this study, $b a_{\mathrm{KPC}}$ genes were present in $23.1 \%$ of carbapenem-resistant Klebsiella isolates. Comparable results have been reported by Helal et al. (32); they used real-time PCR to detect $b l_{\mathrm{KPC}}$ among Enterobacteriaceae in Cairo University Hospital and found that $22 \%$ of carbapenem-resistant Klebsiella strains harboured bla ${ }_{\mathrm{KPC}}$ genes. In Germany, Kaase et al. (33) observed that $35.3 \%$ of carbapenem-resistant Klebsiella isolates produced KPC. There is evidence that carbapenem resistance in Enterobacteriaceae is an increasing problem and may dangerously limit treatment options (33). In the current study, the $b l a_{\mathrm{KPC}}$ gene was not detected in $(76.9 \%)$ of resistant isolates. This may be due to the presence of a carbapenemase other than KPC carbapenemase or to a resistance mechanism other than carbapenemase production (34).

\section{Limitations of the study}

The primary limitation is that no other carbapenemase discs (other than imipenem, meropenem and ertapenem) were used for screening for carbapenamase production due to the unavailability of the antibiotic discs. The second limitation is that a history of taking antimicrobials during the preceding 3 months should have been an exclusion criterion, yet we could not apply this due to the lack of medical records. Data reported by patients about their use of antibiotics could be inacurate.

\section{Conclusions}

Although the recorded rates of VAP in this study are lower than those found in some previous studies, VAP is still a challenge in the ICU. The high prevalence of Gram-negative bacilli and the increased rates of carbapenem resistance among Klebsiella isolates highlight the urgent need for the proper implementation of antibiotic stewardship programmes.

\section{Recommendation}

Strict implementation of VAPprevention strategies are needed with continuous monitoring of the spread of antibiotic-resistant strains.

\section{Funding: None.}

Competing interests: None declared.

\section{References}

1. Xie DS, Xiong W, Lai RP, Liu L, Gan XM, Wang XH, et al. Ventilator-associated pneumonia in intensive care units in Hubei Province, China: a multicentre prospective cohort survey. J Hosp Infect. 2011;78(4):284-88.
2. Krishnamurthy V, Vijay Kumar GS, Prashanth HV, Prakash R, Kumar MS. Ventilator associated pneumonia: bacterial isolates and its antibiotic resistance pattern. Int J Biol Med Res. 2013;4(2):3135-38. 
3. Girgis SA, Othman HB, Kassem NN, Abdou SM. Evaluation of boronic acid disk for detection of Klebsiella pneumoniae carbapenemase in Klebsiella pneumoniae. Int J Curr Microbiol App Sci. 2015;4(5):772-83.

4. Sureka RK, Deodurg PM, Doddamani PK. Antibiogram of Pseudomonas aeruginosa isolated from ventilator associated pneumonia in a tertiary care hospital. World J Pharm Res. 2014; 3(2):2834-41.

5. Ranjan N, Chaudhary U, Chaudhry D, Ranjan KP. Ventilatorassociated pneumonia in a tertiary care intensive care unit: analysis of incidence, risk factors and mortality. Indian J Crit Care Med. 2014;18(4):200-4.

6. Pneumonia (ventilator-associated [VAP] and non-ventilatorassociated pneumonia [PNEU]) event. In: Centers for Disease Control and Prevention [website]. Atlanta, GA: Centers for Disease Control and Prevention; 2016 (http://www.cdc.gov/ nhsn/pdfs/pscmanual/6pscvapcurrent.pdf, accessed 8 June 2016).

7. Bodi M, Rodriguez A, Sole-Violan J, Gilavert MC, Garnacho J, Blanquer J, et al. Antibiotic prescription for communityacquired pneumonia in the intensive care unit: impact of adherence to Infectious Diseases Society of America guidelines on survival. Clin Infect Dis. 2005;41(12):1709-16.

8. Kiser K, Payne W, Taff T. Cultivation of microorganisms. In: Clinical laboratory microbiology: a practical approach, first edition. San Francisco: Pearson; 2011:142-61.

9. Bergmans DC, Bonten MJ, De Leeuw PW, Stobberingh EE. Reproducibility of quantitive cultures of endotracheal aspirates from mechanically ventilated patients. J Clin Microbiol. 1997;35(3):796-98.

10. Joseph NM, Sistla S, Dutta TK, Badhe AS, Parija SC. Ventilator-associated pneumonia: a review. Eur J Intern Med 2010;21(5):360-68.

11. Cheesbrough M. Biochemical tests to identify bacteria. In: District laboratory practice in tropical countries: part 2, first edition. Cambridge: Cambridge University Press 2006;62-70.

12. Clinical and Laboratory Standards Institute. Performance standards for antimicrobial susceptibility testing: twenty-fifth informational supplement. Wayne, PA: Clinical and Laboratory Standards Institute; 2015 (CLSI document M100-S25).

13. Magiorakos AP, Srinivasan A, Carey RB, Carmeli Y, Falagas ME, Giske CG, et al. Multidrug-resistant, extensively drug-resistant and pandrug-resistant bacteria: an international expert proposal for interim standard definitions for acquired resistance. Clin Microbiol Infect. 2012;18(3):268-81.

14. Schechner V, Straus-Robinson K, Schwartz D, Pfeffer I, Tarabeia J, Moskovich R, et al. Evaluation of PCR-based testing for surveillance of KPC producing carbapenem-resistant members of the Enterobacteriaceae family. J Clin Microbiol. 2009;47(10):3261-65.

15. Mohammed HS. Ventilator bundle approach for reduction of ventilator associated pneumonia in respiratory intensive care unit at Ain Shams University Hospital, M.Sc. Thesis in chest medicine, faculty of medicine, Ain Shams university, 2011.

16. Abdel-Latif W, Erfan D. The impact of improvement project on ventilator associated pneumonia incidence rate at Nasser institute intensive care unit in Cairo. Egypt J Med Lab Sci. 2013;22(2):205-20.

17. Al-Dorzi HM, El-Saed A, Rishu AH, Balkhy HH, Memish ZA, Arabi YM. The results of a 6-year epidemiologic surveillance for ventilator-associated pneumonia at a tertiary care intensive care unit in Saudi Arabia. Am J Infect Control. 2012;40(9):79499.
18. Mehta A, Rosenthal VD, Mehta Y, Chakravarthy M, Todi SK, Sen $\mathrm{N}$, et al. Device-associated nosocomial infection rates in intensive care units of seven Indian cities: findings of the International Nosocomial Infection Control Consortium (INICC). J Hosp Infect. 2007;67(2):168-74.

19. Rosenthal VD, Maki DG, Salomao R, Moreno CA, Mehta Y, Higuera F, et al. Device-associated nosocomial infections in 55 intensive care units of 8 developing countries. Ann Intern Med. 2006;145(8):582-91.

20. Edwards JR, Peterson KD, Andrus ML, Dudeck MA, Pollock DA, Horan TC. National Healthcare Safety Network (NHSN) report, data summary for 2006 through 2007, issued November 2008. Am J Infect Control. 2008;36(9):609-26.

21. Rakshit P, Nagar VS, Deshpande AK. Incidence, clinical outcome, and risk stratification of ventilator-associated pneumonia-a prospective cohort study. Indian J Crit Care Med. 2005;9(4):211-16

22. Lebessi E, Dellagrammaticas H, Tassios PT, Tzouvelekis LS, Ioannidou S, Foustoukou M, et al. Extended-spectrum $\beta$-lactamase-producing Klebsiella pneumoniae in a neonatal intensive care unit in the high-prevalence area of Athens, Greece. J Clin Microbiol. 2002;40(3):799-804.

23. Raza M, Chander A, Ranabhat A. Antimicrobial susceptibility patterns of the bacterial isolates in post-operative wound infections in a tertiary care hospital, Kathmandu, Nepal. Open J Med Microbiol. 2013;3(3):159-63.

24. Amer FA, Elbehedy EM, Elahmady M. Streptococcus peumoniae in an Egyptian urban community: incidence of erythromycin-resistance determinants and antibiotic susceptibility profile. Asian Pac J Trop Med. 2008;1(94):20-23.

25. Paterson DL. Resistance in Gram-negative bacteria: Enterobacteriaceae. Am J Med. 2006;119(6 Suppl. 1):S20-28.

26. El-Kholy A, Saied T, Gaber M, Younan MA, Haleim MM, ElSayed $\mathrm{H}$, et al. Device-associated nosocomial infection rates in intensive care units at Cairo University hospitals: first step toward initiating surveillance programs in a resource-limited country. Am J Infect Control. 2012;40(6):e216-20.

27. Sievert DM, Ricks P, Edwards JR, Schneider A, Patel J, Srinivasan A, et al. Antimicrobial-resistant pathogens associated with healthcare-associated infections: summary of data reported to the National Healthcare Safety Network at the Centers for Disease Control and Prevention, 2009-2010. Infect Control Hosp Epidemiol. 2013;34:1-14.

28. Marschall J, Tibbetts RJ, Dunne WM, Frye JG, Fraser VJ, Warren DK. Presence of the KPC carbapenemase gene in Enterobacteriaceae causing bacteremia and its correlation with in vitro carbapenem susceptibility. J Clin Microbiol. 2009;47(1):239-41.

29. Arnold RS, Thom KA, Sharma S, Phillips M, Johnson JK, Morgan DJ. Emergence of Klebsiella pneumoniae carbapenemase (KPC)- producing bacteria. South Med J. 2011;104(1):40-45.

30. Tumbarello M, Trecarichi EM, Bassetti M, De Rosa FG, Spanu $\mathrm{T}$, Di Meco E, et al. Identifying patients harboring extendedspectrum- $\beta$-lactamase-producing Enterobacteriaceae on hospital admission: derivation and validation of a scoring system. Antimicrob Agents Chemother. 2011;55(7):3485-90.

31. Freitas AL, Machado DP, Soares FD, Barth AL. Extended spectrum $\beta$-lactamases in Klebsiella spp. and Escherichia coli obtained in a Brazilian teaching hospital: detection, prevalence and molecular typing. Braz J Microbiol. 2003;34(4):344-48.

32. Helal SF, El-Rachidi NG, AbdulRahman EM, Hassan DM. The presence of blaKPC-mediated resistance in Enterobacteriaceae in Cairo University hospitals in Egypt and its correlation with in vitro carbapenem susceptibility. J Chemother. 2014;26(2):125-28. 
33. Kasse M, Szabados F, Wassill L, Gatermann SG. Detection of carbapenemases in Enterobacteriaceae by a commercial multiplex PCR. J Clin Microbiol. 2012;50(9):3115-18.

34. Shanmugam P, Meenakshisundaram J, Jayaraman P. blaKPC gene detection in clinical isolates of carbapenem resistant Enterobacteriaceae in a tertiary care hospital. J Clin Diagn Res. 2013;7(12):2736
35. Hindler JA, Humphries RM. Colistin MIC variability by method for contemporary clinical isolates of multidrug-resistant Gramnegative bacilli. J Clin Microbiol. 2013;51(6):1678-84. 